\title{
ESTUDO DO TRATAMENTO DE EFLUENTES UTILIZANDO RESÍDUOS AGROINDUSTRIAIS
}

\author{
F. B. P de FARIAS ${ }^{1}$, J. N. N. PEREIRA ${ }^{1}$, T. A. V. CARLOS ${ }^{1}$, Z. M. $\operatorname{dos}$ SANTOS $^{1}$ e M. V. P. \\ ROCHA $^{2}$
}

${ }^{1}$ Universidade Federal Rural do Semi-Árido, Departamento de Agrotecnologia e Ciências Sociais

2 Universidade Federal do Ceará, Departamento de Engenharia Química E-mail para contato: zilvammelo@ufersa.edu.br

\begin{abstract}
RESUMO - Com o intuito de minimizar os impactos ambientais causados pelas indústrias têxteis, através da reutilização da água nos processos de produção, foi realizado um estudo de adsorção que teve como adsorvente o bagaço de caju, sendo este escolhido por ter uma série de fatores positivos, como baixo custo, fácil obtenção e no decorrer do experimento observou-se que também é responsável por um alto potencial de adsorção. O corante utilizado no estudo foi Azul Reativo MR GG 80\%. Posteriormente, foram realizadas três cinéticas de adsorção, estas tendo como fator variante a concentração do adsorvato (120, 180 e 230 ppm), no intuito de estudar a influência desta no processo de adsorção e determinar o tempo de equíbrio cinético, que foi de 24 horas. Dois modelos cinéticos foram aplicados aos experimentos, o pseudo-primeira ordem e pseudo-segunda ordem, sendo que o modelo de pseudo-segunda apresentou melhores resultados $\left(R^{2}=0,9966 ; R^{2}=\right.$ 0,$9949 ; R^{2}=0,9955$; para as três concentrações, respectivamente). Em relação às isotermas, que teve como variável a temperatura $\left(30,37 \mathrm{e} 45^{\circ} \mathrm{C}\right)$ a quantidade adsorvida aumentou com o aumento desta, o que indicou ser um processo endotérmico e foram aplicados os modelos de Langmuir, Freundlich, Tóth e Langmuir-Freundlich, onde o modelo de Tóth se ajustou melhor aos dados experimentais e através dele obteve-se uma quantidade máxima de adsorção. Na avaliação termodinâmica, os parâmetros $\left(\Delta H^{\mathrm{o}}, \Delta S^{\mathrm{o}} \mathrm{e}\right.$ $\Delta G^{0}$ ) indicaram um processo endotérmico, espontâneo e com indícios de quimissorção. $\mathrm{O}$ bagaço de caju sem tratamento algum se mostrou muito eficaz no processo de adsorção, tendo altos índices de remoção do corante. Portanto, através desse estudo, surgem perspectivas positivas quanto ao emprego do bagaço de caju como adsorvente nos processos de adsorção.
\end{abstract}

\section{INTRODUÇÃO}

Atualmente os impactos ambientais causados pelas indústrias têxteis são bem significativos, já que no decorrer dos processos indústrias tem-se uma expressiva quantidade de efluentes que são lançados nos rios e lagos, agredindo desde a biodiversidade marinha até os próprios seres humanos (Santos, 2011).

A partir destes fatos, buscam-se diversas formas de combater ou minimizar estes impactos causados pelos efluentes têxteis, dos quais se destacam a troca iônica, ultrafiltração, eletrodiálise, adsorção entre outros (Mitter, 2008). 
A adsorção é uma técnica que envolve a retenção de um ou mais constituintes (adsorvatos) de uma fase fluida (adsortivo) para uma superfície de uma fase sólida (adsorvente). Ela vem sendo usada em grande escala industrial, o que se dá pelo fato deste método associar grandes taxas de remoção com baixos custos. Outro fator positivo, é que em alguns casos o adsorvente pode ser regenerado ao final do processo, ou seja, sem perda da sua identidade (Magdalena, 2010).

O adsorvato em análise é o corante reativo MR GG $80 \%$. Os corantes reativos são os mais populares na manufatura têxtil, devido as suas características favoráveis à rapidez de tingimento, facilidade de operação e baixo consumo na energia de aplicação (Guarantini e Zanoni, 2000). Estruturalmente, apresentam características aniônicas devido à presença de grupos sulfonatos em suas estruturas moleculares (Zanoni, et. al. 2006; Koprivanac et. al. 2005; Souza, et.al. 2010), os quais podem ser vistos de acordo com a Figura 1:
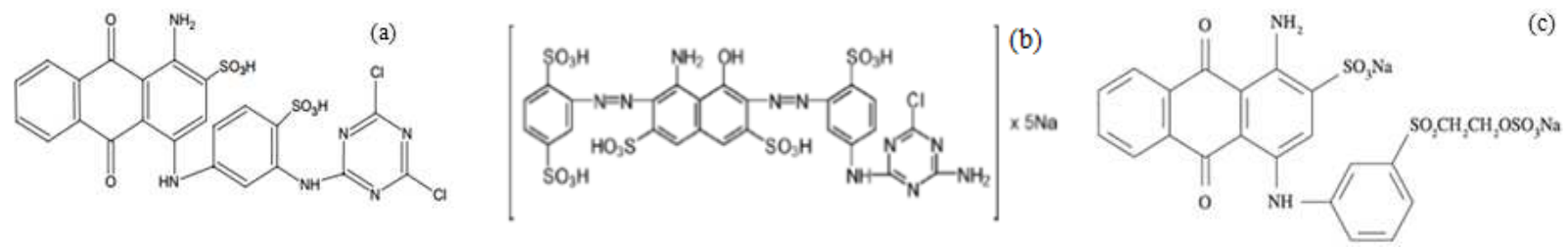

Figura 1 - Estruturas dos corantes (a) azul reativo 4, (b) azul 5G e (c) azul reativo QR-19.

O carvão ativado é um dos adsorventes mais utilizados na remoção de impurezas de gases e líquidos devido a sua alta capacidade de adsorção, já que, possuem uma estrutura porosa bem desenvolvida e esta capacidade de adsorção está associada principalmente com a distribuição de tamanho e volume de poros e uma significativa área superficial. Porém, este apresenta algumas desvantagens como alto custo, ineficiências em alguns tipos de corantes e processos de regeneração (Shimell, 2008).

$\mathrm{Na}$ tentativa de substituir o carvão ativado procuram-se adsorventes preferencialmente naturais, com boa capacidade de adsorção e que sejam abundantes na natureza objetivando baratear as técnicas de adsorção (Mitter, 2008).

O adsorvente alternativo a ser estudado é o bagaço de caju, que é um material lignocelulósico, cuja composição de constituinte varia de acordo com a natureza do adsorvente. Em geral, o maior componente é a celulose (35-50\%), seguido da hemicelulose (20-35\%) e lignina (10-25\%), tais constituintes apresentam características catiônicas ao adsorvente devido à presença de grupos de hidroxila em sua estrutura (Aristidou e Penttilä, 2000).

O bagaço de caju foi escolhido como adsorvente já que este é de fácil acesso e de baixo custo devido o Brasil ser um dos maiores produtores mundiais de caju e a região do nordeste ser responsável por 95\% desta produção (EMBRAPA, 2003).

O estudo a seguir explicita um destino deste bagaço de caju que é gerado nas indústrias de suco e, por não apresentar grandes valores econômicos, não são aproveitados. Como também visa comparar o poder de adsorção do bagaço de caju com o do carvão ativado. E, por fim, avaliar as propriedades termodinâmicas para uma maior compreensão do processo adsortivo, assim como realizar estudos cinéticos e isotérmicos com o bagaço de caju na remoção do corante azul reativo. 


\section{MATERIAIS E MÉTODOS}

\subsection{Materiais}

O bagaço de caju, que foi gentilmente fornecido pela Indústria de Processamento de Sucos Jandaia, Ceará, Brasil, soluções de adsorvato preparadas a partir do corante Azul Reativo MR GG $80 \%$ apresentando um comprimento de onda máximo, $\lambda_{\max }$ de $620 \mathrm{~nm}$, que foi cedido pela Empresa Texpal Indústria Química S/A.

\subsection{Métodos}

Preparo do Adsorvente: O bagaço de caju passou sucessivas lavagens com água destilada. Posteriormente, foi levado à estufa (Tecnal, TE-394/1, Piracicaba, São Paulo) à $60{ }^{\circ} \mathrm{C}$ por $24 \mathrm{~h}$. Após a secagem, este foi triturado, peneirado e estocado. Na etapa de peneiramento, a porção de bagaço que atingiu uma granulometria entre 35 e 65 Mesh, foi usada no procedimento experimental.

Ponto de Carga Zero (PCZ): Pesou-se uma massa do adsorvente e deixou em contato com água destilada em diferentes $\mathrm{pH}$ 's, onde foi utilizado quantidades apropriadas de solução de $\mathrm{HCl}$ $0,01 \mathrm{~mol} / \mathrm{L}$ ou $\mathrm{NaOH} 0,01 \mathrm{~mol} / \mathrm{L}$, quando necessário. A proporção de $0,2 \mathrm{~g}$ de adsorvente para cada $100 \mathrm{~mL}$ de solução foi utilizada. Assim, 11 diferentes pH's iniciais (variando de 2 a 12). As amostras ficaram sob agitação em 160 RPM a $30^{\circ} \mathrm{C}$, usando um agitador orbital (Tecnal, Modelo TE-420) por $24 \mathrm{~h}$. Após este tempo, o $\mathrm{pH}$ das amostras foram medidos usando um phmetro (Tecnal, MPA 210). Assim, foi obtido um gráfico de $\mathrm{pH}$ final em função do $\mathrm{pH}$ inicial.

Cinética de Adsorção: Inicialmente, quantidades fixas de adsorvente foram postas em contato com soluções de corante (em diferentes concentrações iniciais - 230, 180 e $120 \mathrm{mg} \mathrm{L}^{-1}$ ) de forma a se obter uma proporção de $0,2 \mathrm{~g} / 100 \mathrm{~mL}$. As amostras ficaram sob agitação em 160 RPM a $30{ }^{\circ} \mathrm{C}$, usando um agitador orbital. Em diferentes intervalos de tempos, alíquotas foram coletadas e, então, centrifugadas (Edutec, Modelo EEQ-9004), por 10 minutos a 4000 RPM. Posteriormente, as amostras foram levadas a análise no espectrofotômetro (Genaka, Modelo UV/Vis-340 G). Os dados experimentais foram modelados utilizando os modelos linearizados de pseudo-primeira-ordem e pseudo-segunda-ordem.

Isotermas de Adsorção: Primeiramente, foram pesadas massas fixas de adsorventes e postas em contato com a solução de adsorvato em diferentes concentrações e $\mathrm{pH} 2$, respeitando-se a proporção de $0,2 \mathrm{~g} / 100 \mathrm{~mL}$. As amostras ficaram em agitação orbital por $24 \mathrm{~h}$ e $160 \mathrm{RPM}$. Os experimentos foram realizados em diferentes temperaturas $\left(30,37\right.$ e $\left.45^{\circ} \mathrm{C}\right)$. Após este tempo, alíquotas foram recolhidas e centrifugadas por 10 minutos a 4000 RPM. Finalmente, as amostras foram levadas para serem analisadas no espectrofotômetro. A fim de descrever os dados experimentais foram empregados os modelos de Langmuir, Freundlich, Tóth e LangmuirFreundlich. 


\section{RESULTADOS E DISCUSSÕES}

\subsection{Determinação do ponto de carga zero (PCZ)}

O resultado do PCZ deu-se através da média dos pontos referente à constância no gráfico para o pH final (Figura 1), onde para bagaço de caju foi de 6,45.

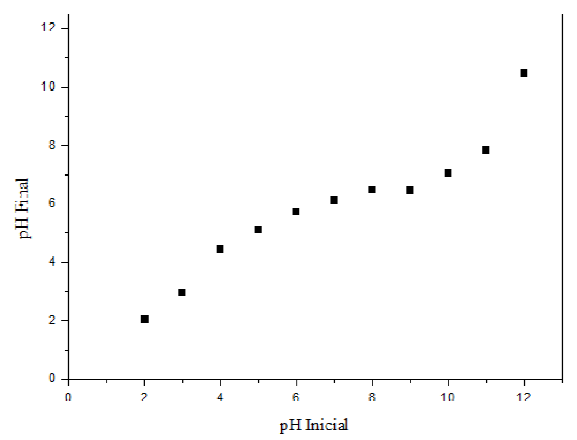

Figura 3 - Determinação do PCZ do bagaço de caju.

$\mathrm{O} \mathrm{pH}$ utilizado nos experimentos está abaixo do pH no PCZ. Assim, acredita-se que a superfície do bagaço de caju deva estar carregada positivamente, uma vez que os grupos hidroxilas (presentes nas moléculas constituintes do bagaço de caju) possam interagir com o ácido presente no meio, como mostra a reação abaixo.

$$
\mathrm{R}-\mathrm{OH}+\mathrm{H}_{3} \mathrm{O}^{+} \rightarrow \mathrm{R}^{-} \mathrm{OH}_{2}^{+}+\mathrm{H}_{2} \mathrm{O}
$$

\subsection{Cinéticas de adsorção do corante azul reativo MR GG $80 \%$}

A partir do estudo cinético obteve-se o tempo de equilíbrio da adsorção, o qual foi de $24 \mathrm{~h}$. Além disso, pode-se também analisar a influência da concentração inicial de adsorvato no processo de adsorção.

A Figura 4.a mostra o modelo de pseudo-primeira, o qual não se ajustou bem aos dados experimentais. Já a Figura 4.b observa-se que se ajustou melhor aos dados experimentais, onde nota-se, ainda, que ao aumentar a concentração do adsorvato, aumenta-se também a quantidade adsorvida. Isso se justifica, pois uma maior concentração de adsorvato aumentará a probabilidade dessas moléculas acessarem sítios que não foram ocupados em concentrações mais baixas.
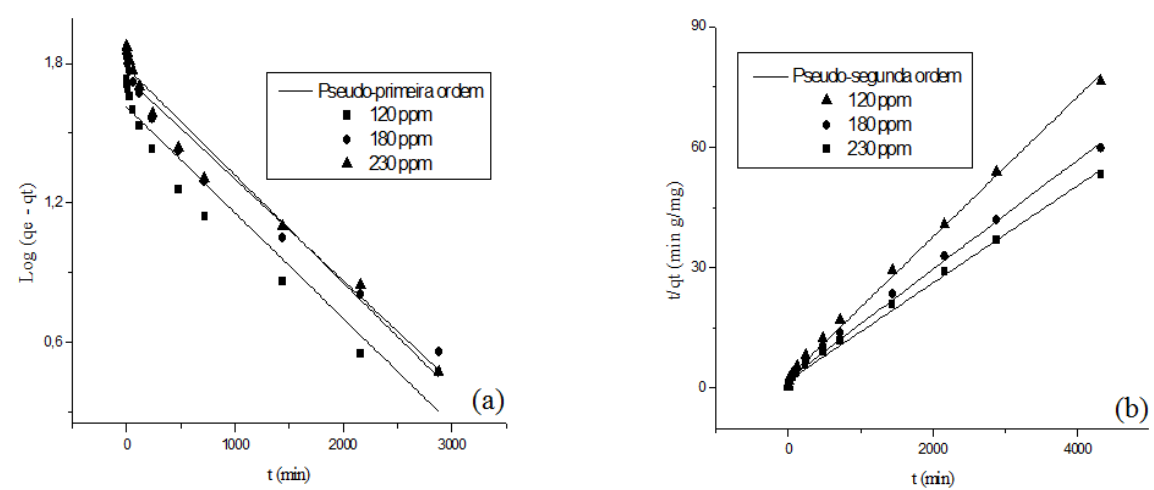

Figura 4 - Cinéticas de adsorção. (a) pseudo-primeira ordem e (b) pseudo-segunda ordem. 
A Tabela 1 compara os parâmetros os modelos cinéticos propostos.

Tabela 1- Aplicação dos modelos de pseudo-primeira ordem e pseudo-segunda ordem.

\begin{tabular}{|c|c|c|c|}
\hline Modelo & $\mathrm{C}_{0}=120 \mathrm{mg} / \mathrm{L}$ & $\mathrm{C}_{0}=180 \mathrm{mg} / \mathrm{L}$ & $\mathrm{C}_{0}=230 \mathrm{mg} / \mathrm{L}$ \\
\hline \multirow{3}{*}{$\begin{array}{c}\text { Pseudo-primeira } \\
\text { ordem }\end{array}$} & $\mathrm{q}_{\mathrm{e} \_ \text {exp }}=56,44 \mathrm{mg} / \mathrm{g}$ & $\mathrm{q}_{\mathrm{e} \_ \text {exp }}=72,45 \mathrm{mg} / \mathrm{g}$ & $\mathrm{q}_{\mathrm{e} \_ \text {exp }}=81,30 \mathrm{mg} / \mathrm{g}$ \\
& $\mathrm{q}_{\mathrm{e} \_ \text {calc }}=40,98 \mathrm{mg} / \mathrm{g}$ & $\mathrm{q}_{\mathrm{e} \_ \text {calc }}=54,32 \mathrm{mg} / \mathrm{g}$ & $\mathrm{q}_{\mathrm{e} \_ \text {calc }}=60,64 \mathrm{mg} / \mathrm{g}$ \\
& $\mathrm{k}_{1}=1,05 \times 10^{-3} \mathrm{~min}^{-1}$ & $\mathrm{k}_{1}=1,01 \times 10^{-3} \mathrm{~min}^{-1}$ & $\mathrm{k}_{1}=1,01 \times 10^{-3} \mathrm{~min}^{-1}$ \\
& $\mathrm{R}^{2}=0,9397$ & $\mathrm{R}^{2}=0,9628$ & $\mathrm{R}^{2}=0,9817$ \\
\hline \multirow{3}{*}{$\begin{array}{c}\text { Pseudo-segunda } \\
\text { ordem }\end{array}$} & $\mathrm{q}_{\mathrm{e} \_ \text {exp }}=56,44 \mathrm{mg} / \mathrm{g}$ & $\mathrm{q}_{\mathrm{e} \_ \text {exp }}=72,45 \mathrm{mg} / \mathrm{g}$ & $\mathrm{q}_{\mathrm{e} \_ \text {exp }}=81,30 \mathrm{mg} / \mathrm{g}$ \\
& $\mathrm{q}_{\mathrm{e} \_ \text {calc }}=57,21 \mathrm{mg} / \mathrm{g}$ & $\mathrm{q}_{\mathrm{e} \_ \text {calc }}=73,47 \mathrm{mg} / \mathrm{g}$ & $\mathrm{q}_{\mathrm{e} \_ \text {calc }}=82,44 \mathrm{mg} / \mathrm{g}$ \\
& $\mathrm{k}_{2}=8,08 \times 10^{-5} \mathrm{~g} / \mathrm{mgmin}$ & $\mathrm{k}_{2}=7,72 \times 10^{-5} \mathrm{~g} / \mathrm{mgmin}$ & $\mathrm{k}_{2}=7,51 \times 10^{-5} \mathrm{~g} / \mathrm{mgmin}$ \\
& $\mathrm{R}^{2}=0,9966$ & $\mathrm{R}^{2}=0,9949$ & $\mathrm{R}^{2}=0,9955$ \\
\hline
\end{tabular}

O modelo de pseudo-segunda ordem ajustou-se melhor aos dados experimentais, pois além de apresentar melhores coeficientes de determinação $\left(\mathrm{R}^{2}\right)$, apresentou ainda valores mais próximos entre as quantidades adsorvidas no equilíbrio (experimental e calculada), em relação ao modelo de pseudo-primeira ordem.

Em relação às constantes de velocidades $\left(\mathrm{k}_{1}\right.$ e $\left.\mathrm{k}_{2}\right)$ observam-se que estas diminuem com o aumento da concentração inicial do adsorvato, o que já seria de se esperar, uma vez que elevando esta concentração é requerido um maior tempo para alcançar as moléculas se acomodarem no adsorvente e alcançarem o novo equilíbrio do sistema.

Ainda em relação aos estudos cinéticos, foram obtidos também os percentuais de remoção nas diferentes concentrações analisadas. Tais resultados foram calculados a partir da equação $1 \mathrm{e}$ estão dispostos na Tabela 1 .

$$
R=100 \frac{\left(C_{0}-C_{f}\right)}{C_{0}}
$$

Onde $C_{0}$ e $C_{f}$ são as concentrações inicial e final, respectivamente.

Tabela 2 - Percentual de remoção do corante azul reativo MR GG 80\%

\begin{tabular}{|c|c|c|}
\hline Concentração Inicial de Adsorvato (mg/L) & Remoção (\%) & Quantidade Adsorvida (mg/g) \\
\hline 120 & 95,53 & 56,44 \\
\hline 180 & 81,41 & 72,45 \\
\hline 230 & 71,87 & 81,30 \\
\hline
\end{tabular}

Observa-se Tabela 2, que a quantidade adsorvida aumenta com o aumento da concentração. Resultados semelhantes foram obtidos por Schneider (2008), onde a quantidade adsorvida aumenta com a elevação da concentração. Já que quando a concentração inicial é maior, aumenta a diferença entre as concentrações dos compostos entre as fases líquida e sólida, assim, aumentando a força motriz à transferência de massa. Além disso, para uma mesma massa de adsorvente existe uma quantidade maior de moléculas disponíveis inicialmente. Assim, a tendência é que uma quantidade maior de moléculas seja adsorvida. 
Ainda em relação à Tabela 2, observa-se uma relação inversa entre a concentração inicial de adsorvato e o percentual de remoção. Uma vez que em baixas concentrações tem-se uma baixa quantidade de moléculas de corante, resultando em uma eficiente adsorção pelo bagaço de caju. O aumento da concentração inicial proporcionará uma elevação significativa de moléculas de corante, proporcionando uma quantidade maior dessas moléculas não adsorvidas em solução devido à saturação do adsorvente, já que este tem o poder de adsorção limitado por possuir uma massa fixa (Schneider, 2008).

\subsection{Isotermas de adsorção do corante azul reativo MR GG $80 \%$}

De acordo com a Figura 5, observam-se três isotermas de adsorção onde o fator variante é a temperatura $\left(30^{\circ} \mathrm{C}, 37^{\circ} \mathrm{C}\right.$ e $\left.45^{\circ} \mathrm{C}\right)$, cada uma é ajustada a alguns modelos encontrados na literatura, como o modelo de Langmuir, Freundlich, Tóth e Langmuir-Freundlich.
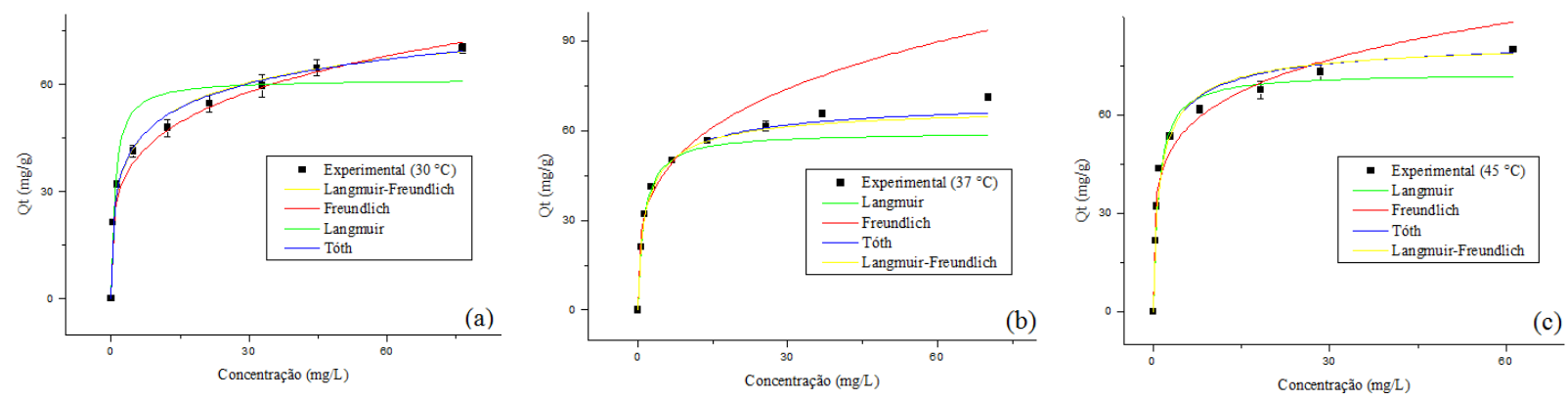

Figura 5 - Isotermas de adsorção (a) a $30^{\circ} \mathrm{C}$ (b) $37^{\circ} \mathrm{C}$ e (c) $45^{\circ} \mathrm{C}$ com modelos de isotermas.

A Tabela 3 apresenta os parâmetros ajustados pelas isotermas e o coeficiente de correlação para cada modelo empregado em cada temperatura estudada para o corante azul reativo MR GG $80 \%$.

Tabela 3 - Aplicação dos modelos de Langmuir, Freundlich, Tóth e Langmuir-Freundlich.

\begin{tabular}{|c|c|c|c|}
\hline Modelo & $\mathrm{T}=30^{\circ} \mathrm{C}$ & $\mathrm{T}=37^{\circ} \mathrm{C}$ & $\mathrm{T}=45^{\circ} \mathrm{C}$ \\
\hline Langmuir & $\begin{array}{c}\mathrm{q}_{\operatorname{máx}}=61,53 \mathrm{mg} / \mathrm{g} \\
\mathrm{K}_{\mathrm{L}}=1,21 \mathrm{~L} / \mathrm{mg} \\
\mathrm{R}^{2}=0,9883 \\
\text { Erro }(\%)=9,28\end{array}$ & $\begin{array}{c}\mathrm{q}_{\max }=59,54 \mathrm{mg} / \mathrm{g} \\
\mathrm{K}_{\mathrm{L}}=0,79 \mathrm{~L} / \mathrm{mg} \\
\mathrm{R}^{2}=0,9992 \\
\text { Erro }(\%)=6,51\end{array}$ & $\begin{array}{c}\mathrm{q}_{\operatorname{máx}}=72,79 \mathrm{mg} / \mathrm{g} \\
\mathrm{K}_{\mathrm{L}}=1,10 \mathrm{~L} / \mathrm{mg} \\
\mathrm{R}^{2}=0,9949 \\
\text { Erro }(\%)=5,95\end{array}$ \\
\hline Freundlich & $\begin{array}{c}\mathrm{K}_{\mathrm{F}}=26,56 \\
\mathrm{n}=4,35 \\
\mathrm{R}^{2}=0,9975 \\
\text { Erro }(\%)=3,77\end{array}$ & $\begin{array}{c}\mathrm{K}_{\mathrm{F}}=28,90 \\
\mathrm{n}=3,62 \\
\mathrm{R}^{2}=0,9963 \\
\text { Erro }(\%)=10,22\end{array}$ & $\begin{array}{c}\mathrm{K}_{\mathrm{F}}=39,64 \\
\mathrm{n}=5,14 \\
\mathrm{R}^{2}=0,9803 \\
\text { Erro }(\%)=9,57\end{array}$ \\
\hline Tóth & $\begin{array}{c}\mathrm{q}_{\text {máx }}=132,89 \mathrm{mg} / \mathrm{g} \\
\mathrm{K}_{\mathrm{T}}=48,74 \\
\mathrm{n}=0,22 \\
\mathrm{R}^{2}=0,9991 \\
\text { Erro }(\%)=2,86\end{array}$ & $\begin{array}{c}\mathrm{q}_{\text {máx }}=72,12 \mathrm{mg} / \mathrm{g} \\
\mathrm{K}_{\mathrm{T}}=1,19 \\
\mathrm{n}=0,64 \\
\mathrm{R}^{2}=0,9993 \\
\text { Erro }(\%)=3,55\end{array}$ & $\begin{array}{c}\mathrm{q}_{\text {máx }}=85,12 \mathrm{mg} / \mathrm{g} \\
\mathrm{K}_{\mathrm{T}}=2 \\
\mathrm{n}=0,63 \\
\mathrm{R}^{2}=0,9976 \\
\text { Erro }(\%)=5,44\end{array}$ \\
\hline Langmuir-Freundlich & $\begin{array}{c}\mathrm{q}_{\text {máx }}=101,64 \mathrm{mg} / \mathrm{g} \\
\mathrm{K}_{\mathrm{LF}}=0,39(\mathrm{mg} / \mathrm{L})^{-1 / n} \\
\mathrm{n}=2,50 \\
\mathrm{R}^{2}=0,9989 \\
\text { Erro }(\%)=3,01\end{array}$ & $\begin{array}{c}\mathrm{q}_{\text {máx }}=68,82 \mathrm{mg} / \mathrm{g} \\
\mathrm{K}_{\mathrm{LF}}=0,63(\mathrm{mg} / \mathrm{L})^{-1 / \mathrm{n}} \\
\mathrm{n}=1,32 \\
\mathrm{R}^{2}=0,9992 \\
\text { Erro }(\%)=4,04\end{array}$ & $\begin{array}{c}\mathrm{q}_{\text {máx }}=83,35 \mathrm{mg} / \mathrm{g} \\
\mathrm{K}_{\mathrm{LF}}=0,83(\mathrm{mg} / \mathrm{L})^{-1 / \mathrm{n}} \\
\mathrm{n}=1,37 \\
\mathrm{R}^{2}=0,9973 \\
\text { Erro }(\%)=5,78\end{array}$ \\
\hline
\end{tabular}


De acordo com os resultados obtidos, pode-se concluir que o modelo que melhor se ajustou aos dados experimentais foi o de Tóth, pois este além de apresentar uma linha mais próxima aos dados experimentais, onde pode observar através da figura 5, apresentou ainda melhores coeficientes de correlação $\left(R^{2}=0,9991 ; R^{2}=0,9993 ; R^{2}=0,9976\right.$; para as temperaturas de 30, 37 e $45^{\circ} \mathrm{C}$ respectivamente) e um menor erro experimental $(2,86 \% ; 3,55$ e $5,44 \%)$ para cada temperatura em relação a todos os outros modelos propostos.

Os parâmetros termodinâmicos $\left(\Delta H^{\mathrm{o}}, \Delta S^{\mathrm{o}}\right.$ e $\left.\Delta G^{\mathrm{o}}\right)$ para o processo de adsorção foram calculados usando a equação de Van’t Hoff (Equação 2).

$$
\ln \left(\frac{q_{e}}{C_{e}}\right)=\frac{\Delta S^{o}}{R}-\frac{\Delta H^{o}}{R T}
$$

Onde $q_{e}$ e $C_{e}$ são a concentração no equilíbrio de corante $(\mathrm{mg} / \mathrm{L})$ e a quantidade de corante adsorvida no equilíbrio $(\mathrm{mg} / \mathrm{g})$. Assim, construiu-se um gráfico de $\ln \left(q_{e} / C_{e}\right)$ em função do inverso das temperaturas avaliadas neste estudo (Figura 6), obtendo-se uma reta. Onde a inclinação e o coeficiente da reta dão o $\Delta H^{0}$ e o $\Delta S^{0}$, respectivamente. A partir destes dados obteve-se a energia livre de Gibbs foi obtida pela relação: $\Delta G^{\mathrm{o}}=\Delta H^{\mathrm{o}}-T \Delta S^{\mathrm{o}}$.

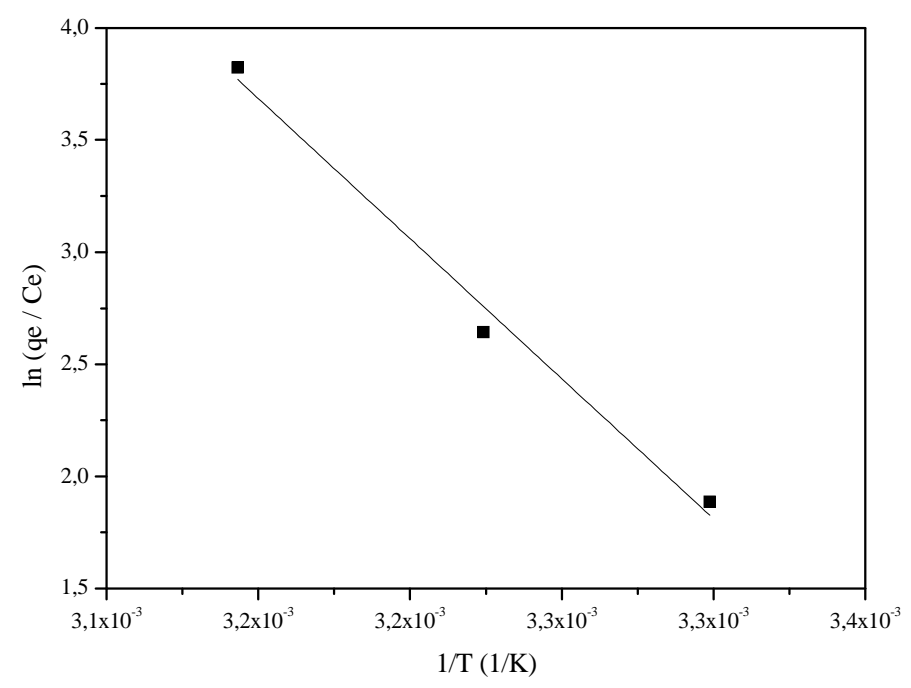

Figura 6 - Determinação do calor e da entropia de adsorção

Os parâmetros termodinâmicos foram obtidos a partir Através dos coeficientes angulares e lineares, obtidos na Figura 6, determinaram-se os parâmetros de calor e entropia de adsorção e, assim, calculou-se a energia livre de Gibbs, onde os dados termodinâmicos estão representados na Tabela 4. 
Tabela 4 - Parâmetros termodinâmicos de adsorção.

\begin{tabular}{|c|c|c|c|}
\hline Temperatura $(\mathrm{K})$ & $\Delta \mathrm{G}^{\circ}(\mathrm{KJ} / \mathrm{mol})$ & $\Delta \mathrm{H}^{\circ}(\mathrm{KJ} / \mathrm{mol})$ & $\Delta \mathrm{S}^{\circ}(\mathrm{KJ} / \mathrm{mol})$ \\
\hline 303,15 & $-4,60$ & \multirow{2}{*}{103,82} & 0,36 \\
\hline 310,15 & $-7,11$ & & \\
\hline 318,15 & $-9,97$ & & \\
\hline
\end{tabular}

Os valores negativos de $\Delta G^{\circ}$ e positivo de $\Delta H^{\circ}$ indicam que a adsorção do corante azul reativo MR GG $80 \%$ é um processo espontâneo e endotérmico. O valor obtido para o $\Delta H^{\circ}$ é da ordem de grandeza de uma reação química, o que é um indício de quimissorção. Segundo Dabrowski (2001) nos processos nos quais ocorre adsorção física, observa-se um processo exotérmico, com decréscimo de $\Delta G^{\circ}$ e $\Delta S^{\circ}$. Já os processos de quimissorção, podem ser exotérmicos ou endotérmicos e neste último caso a quantidade de corante adsorvido tende a aumentar de acordo com o aumento da temperatura. Já o valor positivo de $\Delta S^{\circ}$ sugere um aumento da aleatoriedade na interface sólido-solução, originada de algumas mudanças estruturais em ambos, adsorvente e adsorvato.

Uma suposição para o processo adsortivo se dá considerando que os corantes azul reativos sempre apresentam grupos $\mathrm{R}_{1}-\mathrm{SO}_{3}{ }^{-}$e, estes, por sua vez, podem estar formando uma ligação covalente com o adsorvente, uma vez que ele está carregado positivamente (ver seção 3.1) como mostra a reação abaixo:

$$
\mathrm{R}_{1}-\mathrm{SO}_{3}^{-}+\mathrm{R}_{2}-\mathrm{OH}_{2}^{+} \rightarrow \mathrm{R}_{1}-\mathrm{SO}_{3}-\mathrm{R}_{2}+\mathrm{H}_{2} \mathrm{O}
$$

Esta suposição concorda com o valor positivo de entropia, pois ao final da reação obtêm-se moléculas de água, as quais são muito pequenas comparadas às moléculas do adsorvente e adsorvato, causando aumento na entropia do sistema.

\section{CONCLUSÃO}

No estudo cinético, observou-se que em 24 horas atingiu-se o equilíbrio do sistema de adsorção, onde o modelo de pseudo-segunda ordem foi o que melhor representou a cinética de adsorção nas três concentrações analisadas.

Em relação ao estudo isotérmico, verificou-se que a quantidade adsorvida aumenta com o aumento da temperatura, caracterizando-se um processo endotérmico, onde o modelo de Tóth foi o que melhor se ajustou aos dados experimentais obtendo-se melhores coeficientes de correlação e menores erros experimentais. Os parâmetros termodinâmicos foram determinados e concordaram com a constatação de que a adsorção foi um processo endotérmico e espontâneo devido ao valor positivo de $\Delta H^{\circ}$ e negativos de $\Delta G^{\circ}$ respectivamente. $O$ valor positivo de $\Delta S^{\circ}$ confirma a afinidade do corante com o adsorvente. $\mathrm{O}$ valor do $\Delta H^{\circ}$ foi da ordem de grandeza de uma reação química $(103,82 \mathrm{KJ} / \mathrm{mol})$ o que é um forte indício de quimissorção.

De posse de todos esses resultados é possível afirmar que o bagaço de caju é um promissor adsorventes, pois além de possuir um grande potencial de adsorção, sua obtenção é de fácil acesso e de baixo custo, o que o torna um adsorvente diferenciado. 


\section{REFERÊNCIAS}

ARISTIDOU, A.; PENTTILÄ, M. Metabolic engineering applications to renewable resource utilization. Current Opinion in Biotechnology, v.11, p.187-198, 2000.

BALDISSARELli, V.Z. Estudo da Adsorção do Corante Reativo Preto 5 Sobre Carvão Ativado: Caracterização do Adsorvente e Determinação de Parâmetros Cinéticos e Termodinâmicos. Dissertação de Mestrado em Química. Universidade Regional de Blumenau. Blumenau, 2006.

DABROWSKI, A. et al. Adsorption of Phenolic Compounds by Activated Carbon - a Critical Review. Chemosphere, v. 25, p. 1049-1070, 2001.

EMBRAPA. Empresa Brasileira de Pesquisa Agropecuária. Cultivo do Cajueiro, jan/2003. Disponível

<http://sistemasdeproducao.cnptia.embrapa.br/FontesHTML/Caju/CultivodoCajueiro/index.htm. Acesso em 16 nov. 2013.

GUARATINI, C. C. I. e ZANONI, M. V. B. "Corantes Têxteis", Química Nova 23, pp. 1- 21. 2000.

KOPRIVANAC, N. KUSIC, H. VUJEVI, D. Influence of iron on degradation of organic dyes in corona. Journal of Hazardous Materials, 117, 2005.

MAGDALENA, C.P. Adsorção de Corante Reativo Remazol Vermelho rb de Solução Aquosa Usando Zeólita de Cinzas de Carvão e Avaliação da Toxidade Aguda com daphnia similis. Dissertação (Mestrado em Ciências na Área de Tecnologia Nuclear - Materiais)Altarquia Associada à Universidade de São Paulo, São Paulo. 151 f. 2010.

MITTER, E. K. Corantes da Indústria Têxtil: Impactos e Soluções. Disponível em: <http://www.rc.unesp.br/biosferas/0020. php>. Acesso em: 16 nov. 2013.

SANTOS, S. Impacto Ambiental Causado Pela Indústria Têxtil. Florianópolis. Santa Catarina, 2011. Disponível em: <http://www.abepro.org.br/biblioteca/ENEGEP1997_T6410.PDF>. Acesso em: 16 nov. 2013.

SCHIMMEL, D. Adsorção Dos Corantes Reativos Azul 5g E Azul Turquesa Qg Em Carvão Ativado Comercial. Dissertação (Mestrado em Engenharia Química) - Universidade Estadual do Oeste do Paraná, Toledo. 99 f. 2008.

SCHNEIDER, E. L. Adsorção de Compostos Fenólicos sobre Carvão Ativado. Dissertação (Mestrado em Engenharia Química) - Universidade Estadual do Oeste do Paraná, Toledo. 93 f. 2008.

SOUZA, et. al. Esferas de quitosana/Fe na degradação do corante Azul QR-19 por processos foto-Fenton utilizando luz artificial ou solar. Departamento de Química, UFPR, 2010.

ZANONI, et. al. Homogeneous photodegradation of C.I. Reactive Blue 4 using a photoFenton process under artificial and solar irradiation. Institute of Chemistry of Araraquara, São Paulo, 2006. 